\title{
1. What is cosmopolitanism?
}

Cosmopolitanism means many things, but ultimately it centers on respect for life - for others, for different cultures, for animals. Cosmopolitans aspire to a better world. They emphasize compassion and equality, democracy and respect for difference. This worldview is at once very old and very new, having gone through many iterations in time and space.

Cosmopolitanism has received enormous attention from sociologists, philosophers, and some political scientists. With a few exceptions (Popke 2006, 2007; Harvey 2009; Warf 2012), it has been largely overlooked by geographers. This lacuna is irritating not only because cosmopolitanism has much to teach geographers, but also because geographers have much to contribute to how cosmopolitanism can offer useful insights into the world. Geographers have written, for example, with considerable sophistication about borders, the nation-state, global cities, immigration, citizenship, care-giving, and numerous other topics that all reflect cosmopolitan ethics.

This volume attempts to synthesize how cosmopolitanism can inform geography and how geography can inform cosmopolitanism. Geographers can utilize cosmopolitan ideals and perspectives to forge a discipline more explicitly humane, better equipped to combat xenophobia and promote empathy, more capable of building bridges over differences and forging alliances, and more able to connect diverse struggles for social justice and human rights. Conversely, geography infuses cosmopolitanism with an appreciation of spatiality, how cosmopolitan goals mean different things in different contexts, how knowledge is always situated and embodied, and a more nuanced understanding of concepts such as distance, scale, borders, geopolitics, globalization, and connectivity. A geographically informed cosmopolitanism grounds its lofty ideals in the realities of local circumstances. By bringing geography and cosmopolitanism into a creative tension, the volume tries to forge linkages that generate synergies and advance the power of both lines of thought to affect positive social change. The book takes up a formidable array of topics to highlight how each and all of them revolves around a common concern to make the world better, to combat racism and xenophobia, to create a healthier and more welcoming place for strangers. Cosmopolitanism is often portrayed as an airy past-time of indulged intellectuals; the intent here is to show that far from being some type of intellectual masturbation, cosmopolitanism is an effective means of linking disparate struggles and concerns. 
Cosmopolitanism can be found at many levels functioning simultaneously. In some cases, cosmopolitan ideals have become institutionalized: through the United Nations, the International Criminal Court, non-governmental organizations, sanctuary cities, immigrant rights movements, animal rights, and other judicial, legal, and political channels. At other times cosmopolitanism operates at a more diffuse scale, in acts of charity, volunteering, struggles against racism and sexism, the fair trade movement, and veganism. Anyone who cares about equality, social justice, human rights, and views all life - human and animal - as meaningful is a cosmopolitan, even if they do not know it.

This introduction first lays out the meanings of cosmopolitanism, which are many and varied. Next it turns to the question as to why it has gained ground over the last several decades. The third section outlines the following chapters.

\section{WHAT IS COSMOPOLITANISM?}

The term "cosmopolitanism" comes from two Greek words, kosmos, meaning "world" and polis, meaning "city." It is often held to originate with the 4th century BC philosopher Diogenes, who famously announced he was a "citizen of the world." The concept has gone through numerous iterations over time and acquired a variety of meanings (Chapter 2). There is no single, universally accepted definition of cosmopolitanism. It is a contested term with multiple interpretations that have varied historically and geographically.

Cosmopolitans are often portrayed as worldly, sophisticated people who travel widely and have many international linkages. This is what Calhoun (2002b, p. 86) means by "the class consciousness of frequent travelers." At other times, cosmopolitanism refers to a particular philosophical position, which may differ from that used in the social sciences (Beck 2004). Sometimes cosmopolitanism is roughly used to mean transnational (Kaunen 2014); it is the ideology of border-crossing, immigration, and diasporas. It is also a means of conceptualizing the Other (Calcutt et al. 2009), of acknowledging and respecting difference and uncoupling it from hierarchies of power and inequality. As Germann Molz (2016, p. 33) puts it, "Cosmopolitanism thus refers to an intellectual skill, an aesthetic savoir faire, and an affective pleasure in experiencing and navigating through cultural difference."

Although it has a lengthy intellectual history, cosmopolitanism is relatively new to academic discourse and to world politics. There are, of course, multiple strains within this intellectual tradition that vary by academic discipline and political emphasis. As we shall see, there are classical, Kantian, religious, Marxist, feminist, and post-colonial versions of cosmopolitanism. Harvey (2000, p. 547) cautions that the growing popularity, and differing uses, of cosmopolitanism mean that it is in danger of becoming "an abstracted discourse with no tangible meaning." Its variegated interpretations imply that the 
philosophy is fluid, adapting to circumstance, but also that it retains a core set of ideas centering on empathy and respect for difference.

Briefly, cosmopolitanism may be defined as an ethical, moral, and political philosophy that seeks to uncouple ethics from distance, arguing that each person is bound up with, and obligated to, humanity as a whole. Cosmopolitanism takes as its explicit ethical point of departure human beings, rather than, say, tribes, nations, or religious communities (Pogge 1992). A cosmopolitan argues for a community among all human beings, regardless of social and political affiliation (Kleingeld and Brown 2013). Cosmopolitans are moral universalists, and insist upon the inherent worthiness and dignity of all individuals, irrespective of their place of birth. For Archibugi (2008, p. 143), "Cosmopolitans may be defined as those who know the world and feel at ease anywhere in it." Cheah (2006b, p. 22) argues it is "a universal humanism that transcends regional particularism." Nussbaum (1994, p. 3) calls it "a set of loyalties to humanity as a whole."

Held (2010, p. 15) holds that cosmopolitanism "recognises each person as an autonomous moral agent entitled to equal dignity and consideration." $\mathrm{He}$ upholds eight principles as undergirding the philosophy: (i) equal worth and dignity; (ii) active agency: (iii) personal responsibility and accountability; (iv) consent; (v) collective decision-making about public matters through voting procedures; (vi) inclusiveness and subsidiarity; (vii) avoidance of serious harm; and (viii) sustainability (p. 69).

Cosmopolitanism is, therefore, simultaneously, a social condition, a philosophical and moral perspective, and a political project. As a social condition, it reflects a world of intense time-space compression, rapid globalization, and the proliferation of intercultural and multicultural linkages. As a philosophy, it celebrates difference and seeks a respectful engagement with the Other, one in which dialogue replaces confrontation. The normative and the positive are fused in the cosmopolitan worldview; as Beck and Sznaider (2006, p. 4) put it, "what cosmopolitanism is cannot ultimately be separated from what cosmopolitanism should be." Politically, cosmopolitanism is dedicated to the construction of transnational institutions, democracy, and world citizenship. Cosmopolitanism is hence inherently personal, political, and geographical in scope. Cosmopolitans seek kinship and allegiance to people everywhere, regardless of where they were born or are located today. It does not allow empathy to succumb to the tyranny of distance.

The cosmopolitan geographical imagination is not limited territorially; it is the antidote to parochialism. It calls for a geographical imagination grounded in empathy and tolerance. It dismisses the nation-state as a historical construct whose time has passed. Adherents of cosmopolitanism take as their "imagined community" not the nation or nation-state, but the world. Cosmopolitanism encourages a reflective distance from one's own culture and cultivates a belief 
in a common humanity, striving for a sense of responsibility not only of the world, but also for the world (Waldron 2000). Morally, therefore, national and cultural boundaries are irrelevant and meaningless, or worse, distractions from the important task of caring for others in light of their shared humanity. Compassion knows no borders, for cosmopolitans recognize humanity wherever it occurs: The value of a human life does not vary across space. In this way, legal and moral cosmopolitanisms are inseparably fused: the ideal global order is one in which all persons are held as moral equals with equivalent rights and duties. Cosmopolitanism is thus deeply intwined with democratic aspirations and practices (Gould 2010). If global citizenship is what it takes to accomplish worldwide equality, so be it.

Cosmopolitanism invites us to think about people relationally, as always interconnected. Such a move puts the ontology of the group above that of the individual, and stands in sharp contrast with the long tradition of Western individualism. In this view, the self is the product of, not the producer, of social relations. Cosmopolitanism also adopts a relational view of space and place, as constructed through webs of flows and linkages. Absolute space, as will be seen, arose in tandem with the nation-state; relational space is far better suited to a post-Westphalian world of global connections.

Cosmopolitanism has long exhibited a tension between universal ideals and simultaneously valuing cultural differences. A common critique of cosmopolitanism is that it is an arrogant, Western ideology imposed on varying cultures throughout the world (Harvey 2009). In the orthodox Kantian version that emerged during the Enlightenment, there was much truth to this criticism. But cosmopolitanism has evolved to take account of the realities of uneven spatial development, of its early Orientalist nature and its post-colonial, subaltern voices. This stance leads to a dialectical interplay between the local and the global, being rooted and being rootless. Commonly cosmopolitanism is interpreted to imply that cosmopolitans reject their local worlds; as Delanty (2006b, p. 26) puts it, "Cosmopolitanism thus reflected the revolt of the individual against the social world, for to be a 'citizen of the world' was to reject the immediately given and closed world of particularistic attachments." Contrary to much received opinion, cosmopolitans do not reject their local roots; rather, they do not privilege them. A more viable view is that of Mendieta (2009, p. 242), who notes that "we can say that cosmopolitanism implicitly recognizes the power of locality, for it stands in tension with it."

The definition of cosmopolitanism used in this volume is deliberately broad, to encompass as many varieties and implications as possible. In this light, the term refers to any and all approaches to the world that reject parochialism, that elevate neighbors over strangers, that portray some groups as superior to others. This view of cosmopolitanism puts a heavy emphasis on empathy and compassion, on respecting differences, and promoting human rights and 
democracy. The volume leans heavily on the famous Stoic notion of concentric circles of compassion (Chapter 2); cosmopolitanism is an attempt to extend these outwards as far as possible. Indeed, serious cosmopolitans advocate for rights not just for the entire human community, but also for animals, and avoid consuming animal products (Chapter 8). In the perspective advocated here, anyone and anything that promotes tolerance, compassion, sympathy, democracy, and respect for difference may be broadly conceived as cosmopolitan, including progressive intellectuals, human and animal rights groups, the United Nations, advocates for immigrants and refugees, and others.

\section{WHY HAS COSMOPOLITAN GAINED SO MUCH ATTENTION?}

While it has enjoyed several moments of popularity historically, cosmopolitanism has made significant gains over the last 30 years, as noted by a burgeoning literature on the topic. Since the end of the Cold War in the 1990s, numerous writers, scholars, and political observers have noted that cosmopolitanism as a political philosophy offers much in an era of rapid and intense globalization. This shift did not take place because large numbers of people suddenly thought it was a good idea. Rather, the surge in cosmopolitanism reflects the shifting historical reality of the current moment, the gradual decline of the nation-state and the emerging post-Westphalian order. As Nyers (2003, p. 1072) argues, "it is clear that the globalization of late modernity has created an historical context for rethinking the possibilities of cultural engagement, social affiliations, legal authority and political action beyond the state." Simply put, cosmopolitanism entails thinking and acting beyond the state, whether city-state or nation-state.

Because the nation-state is so deeply engrained in our ways of thinking, this is no mean feat. Yet just as the emergence of the nation-state in the 17th and 18th centuries produced new forms of organization, territorial management, and identities, so too has the post-Westphalian system called for new ways of thinking about space, power, and identities. Globalization allows more people to view and read about other parts of the world, consume products from different cultures, travel overseas, and meet the Other than at any point in human history. Given the hyperconnectedness of digital capitalism, more people are confronted with difference than ever before.

Cicchelli (2014) holds that a cosmopolitan perspective aids individuals in coping with the complexity of an increasingly globalized society. Globalization has brought disparate groups into contact and made once-solid boundaries more permeable and porous. Viewing the world in a cosmopolitan way facilitates coping with difference, communicating across cultural boundaries, and appreciating how distant events affect one's life. It is precisely through "mobility, reflexivity and an insatiable curiosity toward other cultures that the 
cosmopolitan acquires the competence to navigate in an increasingly diverse and hybridized global context" (Germann Molz 2005, p. 519). As detailed in Chapter 8, cosmopolitanism is deeply intertwined with everyday life and practices. Cosmopolitanism allows one to view the Other as simply different, not better or worse. Difference is a source of delight, not fear. Openness to alterity thus allows one to view borders and communities as constructed, not natural, and fend off the ravenous xenophobia that has accompanied the backlash against globalization.

The social movements that have created, and are creating, a cosmopolitan world have deep historical roots. As several scholars have shown, there has been a long-term secular trend toward greater compassion (Rifkin 2009) and lower rates of violence (Pinker 2012) over time. Modern movements exhibit cosmopolitan intents and goals even if they do not call themselves such. The abolitionist movement of the 19th century was one. So was the civil rights and women's rights movements. Today, these have been joined by immigrant rights, gay rights, and animal rights groups. Movements against torture and abuse by tyrants count as cosmopolitan. So do non-governmental organizations concerned about the poor, disabled, sick, elderly, and children. There are thousands upon thousands of such organizations (Hawken 2007). Cosmopolitanism has enjoyed successes, such as the Universal Declaration of Human Rights, peacekeeping missions, and the International Criminal Court, and defeats, such as outbreaks of ethnic violence (Yugoslavia, Rwanda, Myanmar) and the wave of nationalist xenophobia that is currently sweeping much of the world.

Globalization has reshaped the contours of everyday life for billions. We routinely consume products, ideas, and images produced in other cultures. Immigration has forced many once-isolated communities to confront the reality of cultural difference. Borders have become increasingly permeable. Travel to different countries for work or pleasure has become routine. Meanwhile, neoliberalism has gutted the state's ability to provide public services, leading to numerous groups that fill the void, often by extending their networks across borders. Dealing with differences, cooperating with strangers, thinking like the Other, learning to empathize - these have become increasingly vital skills in a global, multicultural economy and global civil society. Cosmopolitanism is not an airy set of impractical liberal ideals, it is a way of negotiating the complexities of the hyperconnected world today.

For many, these notions are odd or alienating, far from their traditions and lived experience. Cosmopolitanism works to create a very different sense of community, one that does not end at national borders but includes the whole world. As Noble (2009, p. 50) notes, "This pragmatic being-together is a cosmopolitan form of 'communality' which is quite different to traditional notions of community." 


\section{PLAN OF THIS VOLUME}

The chapters that follow take up cosmopolitanism in numerous contexts and approach it from a variety of angles. Throughout, it argues that despite its different interpretations and applications, cosmopolitanism offers a perspective on social life that foregrounds empathy, caring, and compassion. Of course, these notions are not new, and not all practices that can be labeled cosmopolitan invoke them to the same degree. Within this loose conceptual scaffolding, it holds that cosmopolitanism has repeatedly and consistently attempted to elevate geographical imaginations beyond local ties, whether they be tribe, city, or nation. It stresses how cosmopolitanism has rejected dichotomies such as in-group/out-group, local and global, native and foreigner, citizen and immigrant, or them and us. The philosophy dismisses parochialism in all its forms, including nationalism. It has promoted constructive engagements with those of different cultures to foster mutual learning, and sought to build bridges over chasms of difference. Cosmopolitanism emphasizes that everyone lives in multiple communities, that barriers are always permeable and transient, and that interdependence is a fact of life whether we acknowledge it or not. Throughout, the book notes how cosmopolitanism has been a tool in struggles for social justice and human rights, upholding the rights of the poor, powerless, and marginalized. In emphasizing the commonalities that unite humanity, cosmopolitanism has manifested itself in everything from treating strangers with kindness and respect to the prosecution of genocidal dictators. These notions underpin foreign policies, campaigns, and institutions that assist those most in need, whether they be victims of wars, hunger, poverty, or political oppression. Not surprisingly, cosmopolitans have been at the forefront in struggles against racism and sexism, in battles for immigrant rights, and even animal rights.

The second chapter offers an overview of the history and variegated meanings of cosmopolitanism. These include its roots in antiquity (the ancient Hebrew and Greek worlds), medieval extensions, and the emergence of modern cosmopolitanism during the Renaissance and Enlightenment. The rise of humanism as a cosmopolitan outlook on the heels of the European colonial conquests is noted. The chapter dwells at length on Immanuel Kant, the foremost modern proponent of cosmopolitanism. It offers up Jeremy Bentham as an extraordinary cosmopolitan thinker years ahead of his time. It then turns to varieties of cosmopolitanism, which has seen Marxist, romantic, reactionary, and religious manifestations. It points to the Nuremberg Trials in the wake of the defeat of the Nazis as a critical moment in the institutionalization of cosmopolitanism and the defense of human rights. Next, it takes up numerous modern cosmopolitan theorists, notably John Rawls, Martha Nussbaum, Ulrich 
Beck, and several others. Finally, it points to the recent growth of feminist and post-colonial cosmopolitan thought.

Chapter 3 turns explicitly to cosmopolitanism's intersections with the discipline of geography. As noted earlier, these ties are as yet tenuous, and there is much to be done. It starts with the issue of caring and empathy, holding that distance should not matter to our empathy and obligations to others: the concerns of distant strangers should be as important as our own. A vibrant literature on geographies of care-giving has shed light on how we are all situated relationally, as beings who both care and are cared for. Next it examines cosmopolitanism's ties to relational space, the view of the world that foregrounds webs, connections, and flows. Like people, places are created relationally. In contrast to the absolute space that underpins the nation-state, relational spaces emphasize how the world's peoples and places are hopelessly entangled with one another. Because cities are often seen as sites of cosmopolitanism, the chapter examines the ideology's linkages to urbane lifestyles; it is in cities that people are most likely to meet the Other face-to-face, and thus to demolish the simplistic stereotypes that feed xenophobia. The high point of this process is global cities, which not only dominate the global economy but are also mixing places for immigrants and cultures from all over the world. They are the fountainheads of the post-Westphalian order. Finally, the chapter examines the critique of cosmopolitanism by famed geographer David Harvey (2009), arguing that while he is correct about the philosophy's Eurocentrism and neglect of difference in its classical version, he overlooks the substantial body of recent work on "cosmopolitanism from below."

The fourth chapter focuses on cosmopolitanism's contentious ties to the nation-state. It offers an overview of this institution and its ideological counterpart, nationalism, which dominates the political landscape of global capitalism. A historical construct with roots in the 17 th century, the nation-state has become so naturalized in popular discourse and consciousness that it appears to many people as given, not made. The chapter then offers a withering critique of nationalism, and why, despite its earlier emancipatory goals, it has degenerated into blind xenophobia. It notes cosmopolitan debates as to whether the philosophy can or cannot be reconciled with nationalism. Next, it observes the changing role of national borders in light of the decline of the Westphalian political system. It then turns to the question of citizenship, a topic about which geographers have had much to say: conventionally linked to territory, citizenship is undergoing a profound transformation in light of globalization, including the rise of dual and multiple citizenship. Finally, it notes that social science has increasingly sought to escape what Agnew (1994) calls the "territorial trap" of limiting analysis to the nation-state, a worldview that marginalizes other, equally important territorialities coming into being. 
In the fifth chapter, globalization is viewed through a cosmopolitan lens. Obviously so much has been written about such an enormous and important topic, so the chapter highlights dimensions of globalization that lend themselves well to a cosmopolitan analysis. Globalization, it is argued, is the dynamic motor simultaneously creating a post-Westphalian order and lending substance to cosmopolitan initiatives, even if unintentionally. It starts by looking at transnational labor movements, in which solidarity among workers crosses national borders. It then turns to the United Nations as the actually existing manifestation of Kant's vision of a world federation of states, emphasizing its roles in peacekeeping, refugee assistance, and humanitarian affairs. The chapter then takes up the thorny question of cosmopolitan global political governance, its relations to global justice, and calls for a world state. If any institution exemplifies the post-Westphalian political order, it is the International Criminal Court, which is portrayed here as a cosmopolitan entity that inhibits dictators from engaging in the mass murder of their people and punishes them when they do. It then turns to non-governmental organizations (NGOs) engaged in a wide variety of cosmopolitan efforts, which have surged in the wake of global neoliberalism. For all their faults, NGOs such as the Red Cross, Doctors Without Borders, Amnesty International, and many environmental groups have sought to smooth the rough edges of globalization. In the same vein, the chapter examines transnational activist networks and grassroots cosmopolitanism, of which the most visible example is the World Social Forum. Finally, the chapter examines the extent to which globalization has reshaped identities, as ever-growing numbers of people self-identify as "citizens of the world."

Immigrants and refugees are particular subjects of cosmopolitan concern. In Chapter 6, it briefly summarizes the history of U.S. policies toward immigration, focusing on recent deportations and the Trump administration's open hostility toward foreigners. It then turns to the European immigration crisis, which has led to a variety of responses. The European Union's vision of "Fortress Europe" has been challenged by the dramatic influx from Africa, the Middle East, and Afghanistan. While some Europeans have welcomed them, several governments have reacted with draconian measures. Similarly, Australia has gone to great lengths to keep immigrants out. In contrast, the cosmopolitan perspective on immigration stresses the Kantian ethic of hospitality, dismissing national borders as mechanisms to perpetuate injustice. It turns to the activities of immigrants' rights groups in several national contexts. The logical extension of these efforts is the open borders and no borders movement, which disregards the Westphalian system altogether. Finally, the chapter turns to diasporic cosmopolitanism, in which immigrant communities form hybrid cultures that link host and home countries. 
Chapter 7 offers an example of applied cosmopolitanism in practice: sanctuary cities. From the roots in the medieval era (and even earlier) to the abolitionist movement to current cities that harbor undocumented immigrants, these places of refuge have long testified to the power of religious cosmopolitanism. Following a brief history, the chapter notes their growth in the U.S., where roughly 300 towns and counties, as well as seven states, offer sanctuary. It then focuses on the Republican Party's war against these places. Next it notes the rise of sanctuary cities in Europe, and finally touches on their presence elsewhere, including human rights cities across the globe.

Cosmopolitanism is not an abstract set of ideals, but can be practiced in the course of everyday life. In Chapter 8 , several dimensions of applied cosmopolitanism are offered. It begins by sketching banal nationalism - the type practiced on flags at home and bumper stickers - and its vernacular, cosmopolitan equivalent. It then turns to cosmopolitan education as a means of inculcating empathy, respect for difference, and training global citizens. Next it reviews several aspects of cosmopolitan consumption, including media, tourism, and fair trade practices. The chapter then extends the circle of empathy to include animals, noting the rise of the animal rights movement, speciesism, and then makes a plea for veganism. Finally, it ventures briefly into the odd world of posthuman cosmopolitanism, which raises difficult but fascinating issues about bioethics, clones, artificial intelligence, and whether humans should even exist at all.

In the conclusion (Chapter 9), the main highlights are summarized, the various threads that run through the book are drawn together, several criticisms of cosmopolitanism are presented along with a defense, and some final thoughts are offered. 